\title{
Aggregation of nano-sized alum-humic primary particles
}

\author{
Wen-zheng Yu ${ }^{\text {a,b,c }}$, Ting Liu ${ }^{c}$, John Gregory ${ }^{b}$, Gui-bai Li ${ }^{c}$, Hui-juan Liu ${ }^{\text {a,* }}$, Jiu-hui Qu ${ }^{\text {a }}$ \\ ${ }^{a}$ State Key Laboratory of Environmental Aquatic Chemistry, Research Center for Eco-Environmental Sciences, Chinese Academy of Sciences, Beijing 100085, China \\ ${ }^{\mathrm{b}}$ Department of Civil, Environmental and Geomatic Engineering, University College London (UCL), Gower Street, London WC1E 6BT, UK

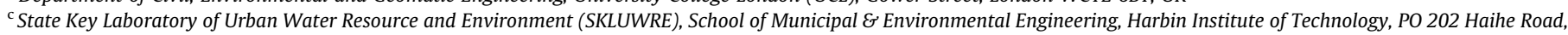 \\ Nangang District, Harbin 150090, China
}

\section{A R T I C L E I N F O}

\section{Article history:}

Received 5 January 2012

Received in revised form 5 August 2012

Accepted 9 August 2012

Available online 24 August 2012

\section{Keywords:}

Coagulation

Lag time

Zeta potential

Brownian motion

Nano-sized primary particles

\begin{abstract}
A B S T R A C T
In order to understand the mechanism of floc formation and growth in coagulation process, effect of zeta potential and surface characteristic of nano sized primary particles on coagulation efficiency were investigated by coagulation of humic acid with alum in this study. It was demonstrated that only 1 min rapid mixing was enough for adsorption of humic acid onto the precipitates of alum, and 15 min flocculation (slow mixing) only induced the formation and growth of flocs. The primary particle size of alum-humic flocs was near $50 \mathrm{~nm}$ and spherical. Mathematical model deduced from Derjaguin-Landau-VerweyOverbeek (DLVO) theory showed that the formation of micro-flocs (or lag time) was determined by the square value of zeta potential of nano-sized primary particles and intensity of Brownian motion, which is closely related to water temperature. There was an absolute critical zeta potential, i.e. $13.5 \mathrm{mV}$ in this study, determining whether two nano-sized particles could overcome the energy barrier consisted of Van der Waals force and electrical double layer repulsion force to allow floc formation to occur at a certain temperature. The Brownian motion determined whether the nano-sized primary particles (aluminum hydroxide precipitates with humic acid) had the opportunity to overcome the repulsive force and cement with each other. Low coagulation efficiency at high latitude area in winter is caused by low collision frequency, which is mainly attributed to the low intensity of Brownian motion at a low temperature. Furthermore, it was demonstrated that aggregation of micro-flocs or their clusters significantly depended on activated sites on the primary particles rather than the zeta potential of primary particles when sweep flocculation dominated the coagulation mechanism if the size of flocs was larger than some value.
\end{abstract}

Crown Copyright (c) 2012 Published by Elsevier B.V. All rights reserved.

\section{Introduction}

Coagulation/flocculation is the most common process to remove particles and other contaminants from water, although the coagulation mechanism has been explored for a long period. The characteristics of flocs formed in the coagulation are influenced by coagulant type and dosage, mixing condition and raw water quality; while the efficiency of solid/liquid separation processes is influenced by characteristics of flocs including floc size and structure.

Dempsey et al. [1,2] and Edwards and Amirtharajah [3] reported that coagulant demand was strongly dependent on humic concentration. For removal of humic substances by hydrolyzing coagulants such as aluminum and ferric salts, two main mechanisms

\footnotetext{
* Corresponding author. Address: State Key Laboratory of Environmental Aquatic Chemistry, Research Center for Eco-Environmental Sciences, Chinese Academy of Sciences, Beijing 100085, China (W.-z. Yu). Tel./fax: +86 1086289160.

E-mail addresses: wzyu@rcees.ac.cn (W.-z. Yu), t75liu@uwaterloo.ca (T. Liu), j.gregory@ucl.ac.uk (J. Gregory), Guibailihit@163.com (G.-b. Li), hjliu@rcees.ac.cn (H.-j. Liu), jhqu@rcees.ac.cn (J.-h. Qu).
}

have been proposed [4,5]: (a) Binding of cationic metal species to anionic sites of the humic material, thus neutralizing charge of humic material at low $\mathrm{pH}$ around 5 or less (charge neutralization). (b) At higher $\mathrm{pH}$, precipitates of amorphous metal hydroxide adsorb the dissolved organic substances (sweep coagulation). All experiments were conducted in this study at $\mathrm{pH}$ much higher than 5 where the second mechanism was dominated. Actually, it is usually not easy to distinguish between the mechanisms of precipitation and adsorption. The results of some study [6] showed that it was mainly determined by $\mathrm{pH}$ and coagulant dosage. Kim et al. [7] found that flocs formed under sweep coagulation were larger and more compact than those formed under charge neutralization. Although the removal of pollutants by coagulation/flocculation has been studied for many years, knowledge of the floc growth mechanism remains limited. Especially, the actual cause of connection between two micro-flocs, especially chemical bonds is still not fully understood.

The collision frequency and growth of aggregates depend on chemical surface of micro-flocs (primary particles) with different dosage and species of coagulant, local shear forces and the suspending 
electrolyte. Chemical surface of micro-flocs may be influenced by temperature, especially at low temperature. Hanson and Cleasby [8] found that the effect of both energy input parameters and flow field characteristics on coagulation performance were insignificant at low temperature. Moreover, Xiao et al. [9] found that low temperature caused slow coagulation rate at early stage, though the zeta potential of flocs formed at low and normal temperature was almost the same. In this study mathematical model was founded to describe the coagulation process and explain the involved mechanisms.

Mathematical model deduced by Dentel [10] was applied to illustrate the coagulation of humic substances by considering them as small colloids with a substantial contribution to surface area in the system, and zeta potential of flocs was average of humic acid and coagulant. Some developed coagulation models differed somewhat from the two mechanisms (charge neutralization and sweep coagulation) in means of explaining destabilization phenomena $[11,12]$. They postulated that, under many conditions, the neutralization and reversal of colloid charge were caused by precipitation of positively charged metal hydroxide. Snodgrass et al. [13] concluded that the rate of complexation of fulvic acid with monomers or small polymers of aluminum was faster than homogeneous growth of aluminum hydroxide nuclei due to the high zeta potential of aluminum hydroxide nuclei. Logan and his students have developed collision theories for fractal objects in 1990s by using latex particles ( 1.48 or $2.84 \mu \mathrm{m}$ ) as the primary particles charged by $\mathrm{NaCl}[14,15]$.

In this study, humic acid was considered as dissolved substance which just changed the charge of alum precipitate. The aim of this study is to better understand the adsorption process of humic acid to alum precipitate and to explore what mainly determines or influences the formation and growth of micro-flocs. The size of primary particles was uniform and near $50 \mathrm{~nm}$. Mathematical model deduced from DLVO theory was utilized to investigate the effect of Brownian motion and zeta potential on the collision of two primary particles, and then on the formation of micro-flocs, where little related publication can be found until now. In addition, the surface activation and quantity of $\eta_{2}-\mathrm{OH}_{2}$ and $\eta_{2}-\mathrm{OH}$ on surface of micro-flocs were discussed to explore the mechanism of micro-floc growth.

\section{Materials and methods}

\subsection{Stock humic acid solution and coagulant}

Four grams of humic acid (Jufeng, Shanghai, China), was dissolved in deionized (DI) water, with $\mathrm{pH}$ adjusted to 7.0, and mixed by a magnetic stirrer for $24 \mathrm{~h}$. Then the suspension was filtered by $0.45 \mu \mathrm{m}$ acetate fiber membrane. The solution was diluted to $500 \mathrm{~mL}$ in a measuring flask and was stored in the dark. Humic acid used here was the same as the one used by Xu et al. [16], and it had been analyzed by them.

Aluminum sulfate hydrate (analytical pure) "alum" was used. Stock alum solution was prepared at a concentration of $0.1 \mathrm{M} \mathrm{Al}$ in DI water.

\subsection{Jar test}

For the flocculation tests, the stock humic acid (HA) was diluted in $1000 \mathrm{~mL}$ tap water (Harbin, China), in a $1.2 \mathrm{~L}$ beaker, to give the test solution with a HA concentration of $4 \mathrm{mg} / \mathrm{L}$. Tap water was left for 1 day to release the residual chlorine. During the jar test, the initial $\mathrm{pH}$ of solution was near 7.0. Total organic carbon (TOC) of the test water was $4.34 \mathrm{mg} / \mathrm{L}$ [17]. The temperature was maintained at $25 \pm 1{ }^{\circ} \mathrm{C}$.
The equipment used in this study was a Flocculator (ZR4-2, Shenzhen Zhongrun, China), which enables mixing speed and time to be preset. The solution was stirred at $50 \mathrm{rpm}$ for $1 \mathrm{~min}$ to $\mathrm{mix}$ uniformly. After that a certain dosage of alum was added with a simultaneous increase of stirring speed to $200 \mathrm{rpm}$. The rapid mixing speed of $200 \mathrm{rpm}$ was maintained for $1 \mathrm{~min}$, and then reduced to $50 \mathrm{rpm}$ for $20 \mathrm{~min}$ or more to allow floc growth to occur.

\subsection{Other methods}

Samples were taken immediately after dosing coagulant and 1 min rapid mixing, and zeta potentials were determined by a zeta sizer (Nano ZS90; Malvern Inc., UK). $\mathrm{UV}_{254}(0.45 \mu \mathrm{m})$ was measured after $1 \mathrm{~min}$ rapid mixing or another 15 min flocculation by an ultraviolet/visible spectrophotometer (U-3010, Hitachi High Technologies Co., Japan). Dissolved organic carbon (DOC) was determined with a total organic carbon (TOC) analyzer (TOC-VCPH, Shimadzu, Japan). The residual Al concentration $(0.45 \mu \mathrm{m})$ was measured by ICP-OES (Perkin-Elmer, USA).

During the slow mixing period, a sample of flocs was taken from below the surface of the solution by a glass tube with an inner diameter of $0.5 \mathrm{~cm}$. The tube was open at both ends; one end of the tube was inserted gently about $25 \mathrm{~mm}$ into the coagulated solution to avoid contacting the stirrer [9]. The flocs in the tube were withdrawn carefully by covering the other end of the tube with a finger. After transferring the sample to a flat mental slide, samples were then air-dried and gold-coated by a sputter and observed under scanning electron microscopy (SEM; JSM7401F, JEDL, Japan).

\subsection{Floc monitoring}

During the coagulation process, sample was siphoned from the stirred jar at $20 \mathrm{~mL} / \mathrm{min}$ through a $3 \mathrm{~mm}$ transparent plastic tube and continuously monitored by a PDA 2000 (Rank Brothers, UK) based on the "turbidity fluctuation" technique [18]. After passing through the monitor, sample was returned to the stirred jar by a peristaltic pump. The experimental procedure was similar to that of Yukselen and Gregory [19]. The average transmitted light intensity (dc value) through the flowing sample and the root-meansquare value (rms) of the fluctuating component are monitored. The ratio ( $\mathrm{rms} / \mathrm{dc}$ ) provides a sensitive measure of particle aggregation and it is often called Flocculation Index (FI). The FI value is strongly correlated with floc size and always increases as flocs grow larger. So the FI value provides a sensitive measure of particle aggregation [18]. In this study, after the FI value reached an initial steady value, coagulant was added into the suspension and the FI value was recorded by a PC data acquisition system at $1 \mathrm{~s}$ intervals.

\section{Results}

\subsection{Zeta potential and $U V_{254}$ removal}

The results in Fig. 1 show the residual $\mathrm{UV}_{254}$ after 1 min rapid mixing and $15 \mathrm{~min}$ flocculation (slow mixing), and zeta potential of micro-flocs after $1 \mathrm{~min}$ rapid mixing at different alum dosages at initial $\mathrm{pH}$ near 7.0. The $\mathrm{pH}$ decreased as the dosage of alum increased, while $\mathrm{UV}_{254}$ decreased from $0.158 \mathrm{~cm}^{-1}$ to $0.154 \mathrm{~cm}^{-1}$ as the $\mathrm{pH}$ decreased from 7.03 to 5.72 (DOC from $4.355 \mathrm{mg} / \mathrm{L}$ to $4.232 \mathrm{mg} / \mathrm{L}$ ). Therefore, the effect of $\mathrm{pH}$ itself on the variation of dissolved NOM could be ignored here. Results in Fig. 1 show that the alum-humic flocs are negatively charged at low alum dosage and that charge reversal occurs at around $0.04 \mathrm{mM} \mathrm{Al}$. The zeta potential increased dramatically increased until $0.08 \mathrm{mM} \mathrm{Al}$, and at 


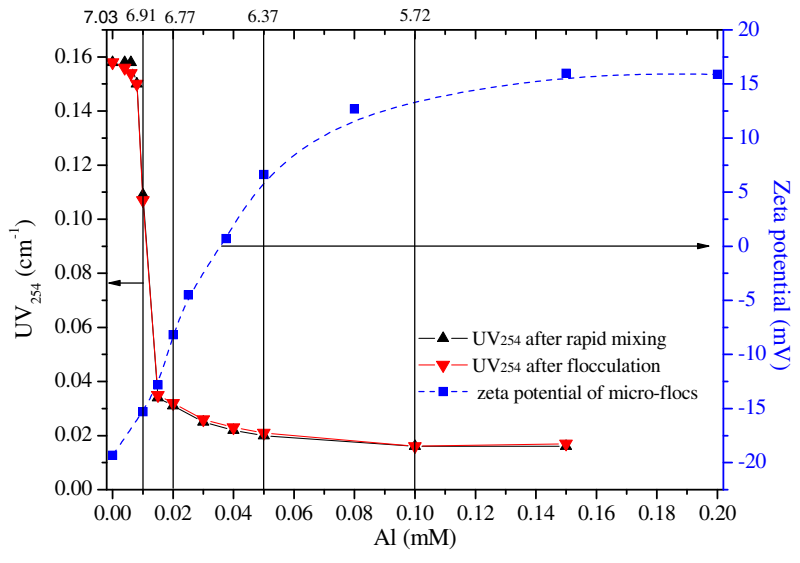

Fig. 1. Residual $\mathrm{UV}_{254}$, zeta potential and $\mathrm{pH}$ at different alum dosages.

higher dosages it increases only slightly and stayed at around $16 \mathrm{mV}$.

There was an appreciable reduction in $\mathrm{UV}_{254}$ at $0.015 \mathrm{mM} \mathrm{Al}$ when zeta potential changed from $-15 \mathrm{mV}$ to $-13 \mathrm{mV}$, and then it was gradually increased at higher dosages. It is clear that there was no significant difference of $U_{254}$ removal between the case of after $1 \mathrm{~min}$ rapid mixing and that of after $15 \mathrm{~min}$ flocculation, as shown in Fig. 1. The results indicated that if the removal of humic substances was achieved by adsorption on precipitated aluminum hydroxide, it could be finished within 1 min or even shorter time after precipitation occurred. The result was confirmed by different waters in different areas of China. It suggested that the flocculation process only improved the size of destabilized particles (flocs), and the mechanism of which will be discussed later.

\subsection{Flocculation index}

In view of coagulant cost and sludge volume in sedimentation tank, the optimal coagulant dosage corresponding to the best coagulation performance is of great importance. Results from continuous monitoring of humic acid coagulation with different alum dosages are shown in Fig. 2. At a very low dosage of $0.01 \mathrm{mM} \mathrm{Al}$ $(-15 \mathrm{mV})$, no change of FI value was observed (data were not shown), which was the same as that formed at a very high dosage of $0.1 \mathrm{mM} \mathrm{Al}(15 \mathrm{mV})$. At a slightly higher dosage of $0.012 \mathrm{mM}$ the FI value began to rise slowly after a long lag time of about $1300 \mathrm{~s}$. However, at the dosages of $0.015-0.08 \mathrm{mM} \mathrm{Al}$, a rapid rise in FI occured soon after no more than $500 \mathrm{~s}$. In these cases, the FI reached a plateau value after a few minutes. Comparing these

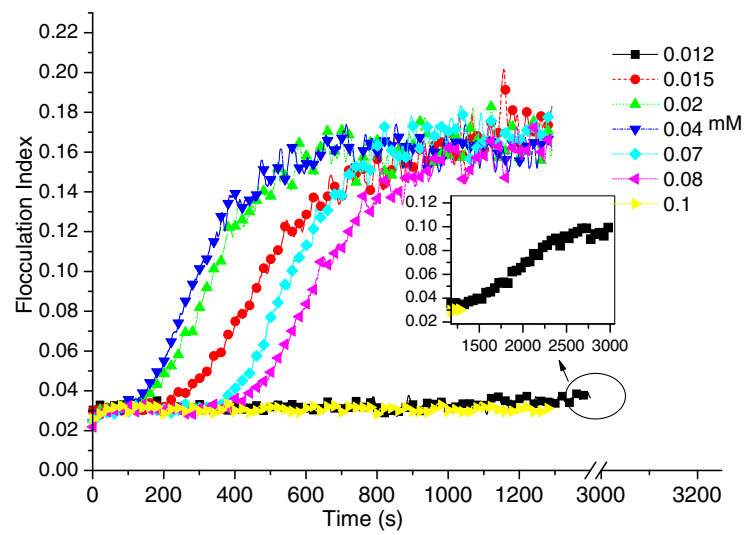

Fig. 2. Effect of alum dosage ( $\mathrm{mM} \mathrm{Al}$ ) on the growth of flocs, as measured by the Flocculation Index. results with the data of zeta potential in Fig. 1, it could be seen that the onset of coagulation was correlated with coagulant dosages, indicating that the absolute value of zeta potential corresponding to a certain dosage should be lower than $13 \mathrm{mV}$ to ensure coagulation process could occur. At the dosage of $0.04 \mathrm{mM} \mathrm{Al}$, the zeta potential was about $0.9 \mathrm{mV}$, which was closed to zero. When the alum dosage was higher than $0.1 \mathrm{mM} \mathrm{Al}$, FI value did not increase and maintained at low value. Moreover, it was also found that the plateau FI values were nearly the same when the dosage changed from $0.012 \mathrm{mM}$ to $0.08 \mathrm{mM} \mathrm{Al}$ in this study.

\subsection{Lag time and coagulation rate}

Flocculation process is very important because the floc properties influence the separation/purification process. There is a variable lag time, depending on coagulant dosage, during which the precipitate particles are ready to aggregate to form flocs, but the aggregates are not yet large enough to give a measurable increase in FI value.

As shown in Fig. 3, when the alum dosage was lower than $0.01 \mathrm{mM} \mathrm{Al}$, the lag time was relatively long, much longer than $1500 \mathrm{~s}$. At a dosage of $0.012 \mathrm{mM} \mathrm{Al}$, the FI value began to rise after a lag time of about $1300 \mathrm{~s}$; while the lag time was less than $500 \mathrm{~s}$ at higher dosages of $0.015-0.08 \mathrm{mM} \mathrm{Al}$, especially at a moderate dosage. However, for a dosage of $0.1 \mathrm{mM} \mathrm{Al}$, the lag time was more than $1500 \mathrm{~s}$, which implied that precipitates of alum were difficult to connect with each other.

From the FI curves in Fig. 2, the coagulation rate (defined by Xiao et al. [9]) as a function of coagulant dosage is shown in Fig. 3. Coagulation rate was found to vary with coagulant dosage. It increased when the dosage of alum was higher than $0.012 \mathrm{mM}$ $\mathrm{Al}$, and then became plateau when the dosages were in the range of 0.02-0.07 $\mathrm{mM} \mathrm{Al}$, even though the zeta potentials corresponding to these alum dosages were different from each other. The results showed that the coagulation rate was determined not only by the zeta potential of micro-flocs, but also by some characteristics of the floc surface, and the result was very similar with the finding of $\mathrm{Fe}$ (III) coagulation by Xiao et al. [20].

\subsection{Relationship between zeta potential and lag time}

What actually cause different lag time of the coagulation process, zeta potential of flocs, surface characteristic of flocs, or others? In order to explain the involved mechanism, absolute values of zeta potential and lag time at different alum dosage were compared with each other. As shown in Fig. 4, with the increasing of alum dosage from 0.01 to $0.10 \mathrm{mM} \mathrm{Al}$, the lag time gradually

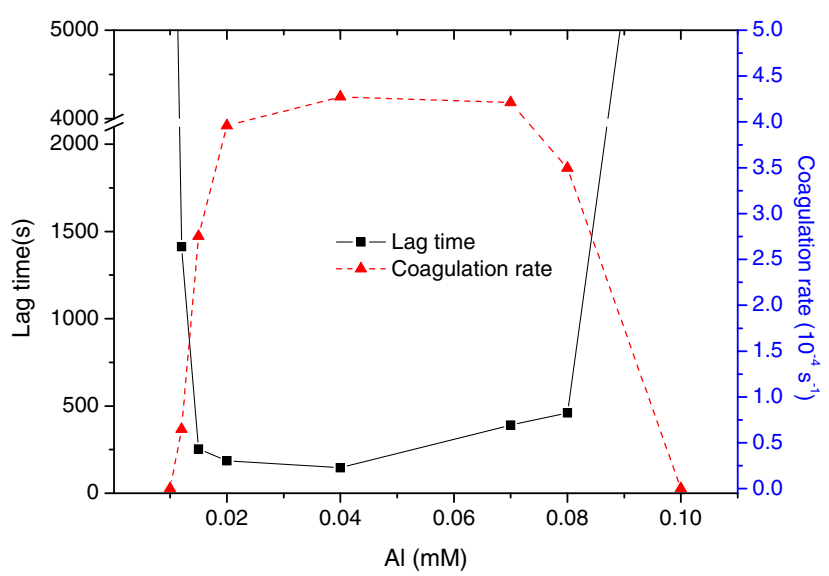

Fig. 3. Effect of alum dosage on the lag time of FI value and coagulation rate. 


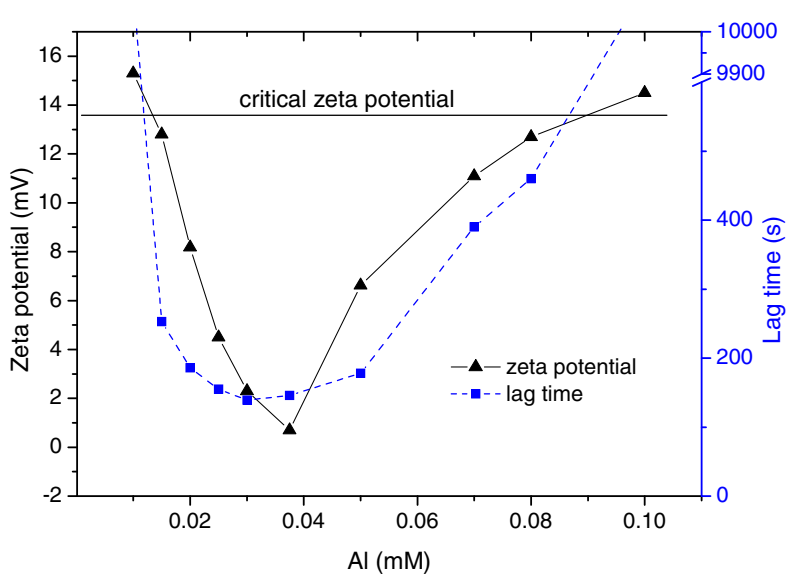

Fig. 4. Relationship between lag time and absolute value of zeta potential.

decreased at first, and the absolute value of zeta potential of flocs also decreased; then both the lag time and the absolute value of zeta potential increased in the later stage. If the absolute value of zeta potential of the flocs was higher than $13.5 \mathrm{mV}$, lag time would increase to infinite time, i.e. stabilization or re-stabilization, whether zeta potential was negative or positive. Thus it can be concluded that there must be a relationship between zeta potential and lag time, which is of great significance in coagulation/flocculation process. Fig. 4 showed that the optimum coagulant dosage was at a zeta potential somewhat offset from zero. Many researchers $[11,21,22]$ also found that the optimum dosage of coagulant was not the dosage when the zeta potential was $0 \mathrm{mV}$ but near $0 \mathrm{mV}$, which may be due to other factors such as solvation and floc volume effects or chemical bonds.

\subsection{Discussion}

In general, perikinetic (diffusion-induced) and orthokinetic (shear-induced) collisions are the two important mechanisms involved in particle transportation. Xiao et al. [9] pointed out that perikinetic collision induced by Brownian diffusion mainly dominates dynamics of particles smaller than $1 \mu \mathrm{m}$; whereas the orthokinetic collision induced by hydrodynamic shear gradients primarily controls the coagulation rate of particles larger than $1 \mu \mathrm{m}$. Therefore, before the FI value increases, the coagulation efficiency is determined by collision frequency;

Humic substances may be considered as either soluble macromolecules or small colloids [10]. In this study, humic substances were assumed as the former, such that the coagulation of them may be modeled by accounting for their substantial contribution to charge on small precipitate particles of alum in the system. The flocs formed by alum and humic acid were consist of thousands of nano-sized primary particles (near $50 \mathrm{~nm}$ ), as shown in Fig 5a. Therefore, the chemical characteristic and reaction dynamics of primary particles was explored here.

When $\mathrm{pH}$ is low, there is little $\mathrm{OH}^{-}$in the solution, and most of existing mode of $\mathrm{Al}^{3+}$ is $\left[\mathrm{Al}\left(\mathrm{OH}_{2}\right)_{6}\right]^{3+}$ and a small part of $\mathrm{Al}^{3+}$ changed into $\left[\mathrm{Al}\left(\mathrm{OH}_{2}\right)_{5}(\mathrm{OH})\right]^{2+}$. As the $\mathrm{pH}$ increases or $\mathrm{Al}^{3+}$ is added into the raw water, some $\left[\mathrm{Al}\left(\mathrm{OH}_{2}\right)_{6}\right]^{3+}$ will deprotonate and change into $\left[\mathrm{Al}\left(\mathrm{OH}_{2}\right)_{6-n}(\mathrm{OH})_{n}\right]^{(3-n)+}$. Then $\left[\mathrm{Al}\left(\mathrm{OH}_{2}\right)_{6-n}(\mathrm{OH})_{n}\right]^{(3-n)+}$ react with humic acid or another $\left[\mathrm{Al}\left(\mathrm{OH}_{2}\right)_{6-n}(\mathrm{OH})_{n}\right]^{(3-n)+}$ to form nano-sized primary particles. After that, Brownian motion will be the force which causes a quick connection between two nano-sized primary particles, by changing $\eta_{2}-\mathrm{OH}_{2}$ and $\eta_{2}-\mathrm{OH}$ into $\mu_{2}-\mathrm{OH}$ and $\mathrm{H}_{2} \mathrm{O}$. The rapid formation of alum flocs can be also explained by the same mechanism. When the hydroxide precipitates with humic acid formed, DLVO theory is considered to be suitable to illustrate the
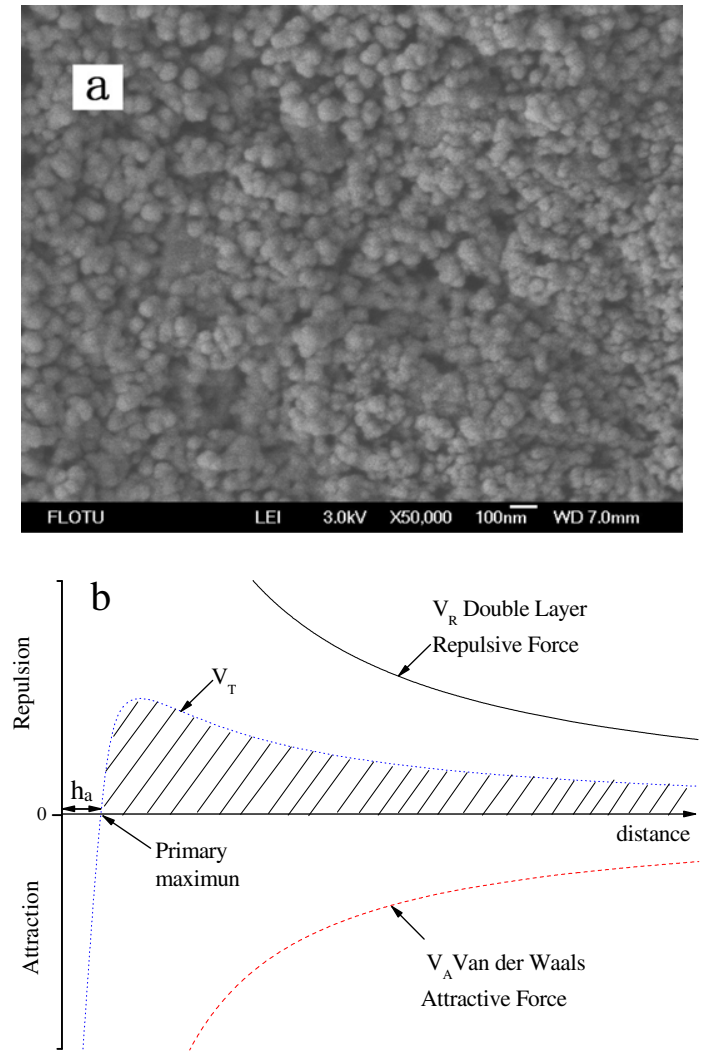

Fig. 5. SEM of alum-humic flocs (a) and schematic diagram of variation of free energy with particle separation according to DLVO theory (b).

process of particle connection, especially between two nano-sized primary particles.

The net energy is given by the sum of double layer repulsive force and Van der Waals attractive force that the particles experience as they approach one another. DLVO theory suggests that the stability of a particle in solution is dependent upon its total potential energy function $V_{T}$. If the ionic strength is low, such as drinking water, there is no secondary minimum, as shown in Fig 5b. This theory recognizes that $V_{T}$ is the balance of several competing contributions [23]:

$V_{T}=V_{A}+V_{R}+V_{S}$

where $V_{S}$ is the potential energy due to the solvent, it usually only makes a marginal contribution to the total potential energy over the last few nanometers of separation. $V_{A}$ is Van der Waals force, and $V_{R}$ is electrical double layer repulsive force. The balance between $V_{A}$ and $V_{R}$ is very important, since they make the attractive and repulsive contributions respectively.

This theory proposes that an energy barrier resulting from the repulsive force prevents two nano-sized particles approaching one another and adhering together (Fig. 5). If the particles with sufficient energy (Brownian motion) can overcome that barrier, the attractive force will pull them into contact and then adhere together strongly and irreversibly, where coagulation/flocculation eventually occurs. In this case, the distance between two particles must be shorter than $h_{a}$, as shown in Fig 5b. Therefore, if the nanosized particles have a repulsive force which is strong enough, the dispersion will give a resistant effect on flocculation and the colloidal system will be stable.

For the interaction between two spherical particles, and here is nano-sized spherical particles, $V_{A}$ is relatively simple as below:

$V_{A}=-\frac{A a}{12 h}$ 
where $A$ is the Hamaker constant, and it is equal to $10.6 \mathrm{kT}$ for water at $25^{\circ} \mathrm{C} ; a$ is radius of particles and $h$ is the particle separation. The repulsive potential $V_{R}$ is a far more complex function. As the size of primary particles was around $50 \mathrm{~nm}, V_{R}$ can be calculated as follow:

$V_{R}=\frac{4 \pi \varepsilon a^{2}}{h+2 a}\left(\frac{k T}{z e}\right)^{2} \xi^{2} \exp (-\kappa h)$

where $\xi$ is the zeta potential, $\kappa$ is a function of the ionic composition, $k$ is Boltzmann constant, $T$ is absolute temperature, $z$ is the valence of counterions, $e$ is the elementary electric charge. $\varepsilon=\varepsilon_{r} \varepsilon_{0}$, where $\varepsilon_{0}$ is the vacuum permittivity and $\varepsilon_{r}$ the relative dielectric constant of the solvent.

$V_{T}=-\frac{A a}{12 h}+\frac{4 \pi \varepsilon a^{2}}{h+2 a}\left(\frac{k T}{z e}\right)^{2} \xi^{2} \exp (-\kappa h)$

The stability of an aqueous dispersion is influenced by three main parameters: surface potential, nature and ionic strength of electrolyte solution, and Hamaker constant. According to our previous research [24] and the result of Xiao et al. [9], zeta potential (or electrophoretic mobility) of flocs will not change as coagulation process continues, even after the flocs are broken, which shows that zeta potential is determined by coagulant dosage and $\mathrm{pH}$ of solution. In addition, ionic strength changed little as the alum dosage increased below a certain value. Hamaker constant is considered constant for a specific system. Thus total attractive force $F$ can be expressed as follows:

$$
\begin{aligned}
F & =-V_{T}=\frac{A a}{12 h}-\frac{4 \pi \varepsilon a^{2}}{h+2 a}\left(\frac{k T}{z e}\right)^{2} \xi^{2} \exp (-\kappa h)=m G \\
& =4 / 3 \pi a^{3} \rho G
\end{aligned}
$$

where $\rho$ is the density of particles, $G$ is the acceleration of particles. The distance between two particles can be calculated as follows:

$H-h(t)=\int_{0}^{t_{F}} v(t) d t=\int_{0}^{t_{F}}\left(v_{0}+\int_{0}^{t} G(t) d t\right) d t$

where $H$ is the distance between two particles, and $v_{0}$ is the statistical highest velocity of particles by Brownian motion and other force at fixed condition. The higher temperature, the higher $v_{0}$ of particles. $v(t)$ is the velocity of primary particles moved towards to other primary particles as function of time. $t_{F}$ is the time needed for the two primary particles to adhere with each other.

$O$ is substituted for $\frac{A a / 12}{4 / 3 \pi a^{3} \rho}$ and $P$ for $\frac{4 \pi \varepsilon \varepsilon_{a} a^{2}}{4 / 3 \pi a^{3} \rho}\left(\frac{k T}{z e}\right)^{2}$.

From formula (5) and (6), it can be calculated that:

$H-h_{a}=v_{0} t_{F}+\int_{0}^{t_{F}}\left(\int_{0}^{t}\left(\frac{O}{h(t)}-\frac{P \xi^{2} \exp (-\kappa h(t))}{h(t)+2 a}\right) d t\right) d t$

where $H$ is the distance between two particles and $h_{a}$ is the distance of adhered particles as shown in Fig. 5b.

Here it is proposed that there is an average value $\bar{h}$, when the distance of particles $h(t)$ changes from $H$ to $h_{a}$.

$\left(\frac{O}{\bar{h}}-\frac{P \xi^{2} \exp (-\kappa \bar{h})}{\bar{h}+2 a}\right) t_{F}^{2}+2 v_{0} t_{F}-2\left(H-h_{a}\right)=0$

Also $M$ is submitted for $\frac{O}{2 h}=\frac{A a / 12}{4 / 3 \pi a^{3} \rho h}$, and $N$ for

$\frac{P \xi^{2} \exp (-\kappa \bar{h})}{2(\bar{h}+2 a)}=\frac{4 \pi \varepsilon \varepsilon_{a} \mathrm{a}^{2}}{4 / 3 \pi \mathrm{a}^{3} \rho}\left(\frac{k T}{z e}\right)^{2} \frac{\xi^{2} \exp (-\kappa \bar{h})}{2(\bar{h}+2 a)}$

So formula (8) can be changed into

$\left(M-N \xi^{2}\right) t_{F}^{2}+v_{0} t_{F}-\left(H-h_{a}\right)=0$
The size of flocs measured by Mastersizer 2000 was very similar with photometric dispersion analyzer (PDA), which is determined by the number concentration of particles (flocs) and their extinction (or scattering) cross sections [24]. The size of flocs here was determined by the number of nano-sized particles, and the effect of fractal dimension of flocs was ignored here. Therefore, lag time here could be linear correlated with $t_{F}$.

$$
\text { If } \begin{aligned}
\overline{V_{A}} & >\overline{V_{R}} \text {, i.e. } M>N \xi^{2}, \text { lag time } \sim t_{F} \\
& =\frac{-v_{0}+\sqrt{v_{0}^{2}+4\left(M-N \xi^{2}\right)\left(H-h_{a}\right)}}{2\left(M-N \xi^{2}\right)}
\end{aligned}
$$

If $\overline{V_{A}}<\overline{V_{R}}$, i.e. $M<N \xi^{2}$, lag time $\sim t_{F}$

$$
=\frac{v_{0}-\sqrt{v_{0}^{2}-4\left(N \xi^{2}-\mathrm{M}\right)\left(H-h_{a}\right)}}{2\left(N \xi^{2}-\mathrm{M}\right)}
$$

If $\overline{V_{A}}=\overline{V_{R}}$, i.e. $M=N \xi^{2}$, lag time $\sim t_{F}=\left(H-h_{a}\right) / v_{0}$

where $v_{0}^{2}-4\left(N \xi^{2}-M\right)\left(H-h_{a}\right)>0$

If absolute $\xi>\left(\frac{v_{0}^{2}+4 M\left(H-h_{a}\right)}{4 N\left(H-h_{a}\right)}\right)^{0.5}$, it is impossible for the particles to adhere with each other, and the lag time will be infinity $(\infty)$. Here the critical zeta potential is near $13.5 \mathrm{mV}$. The higher temperature is, the higher $v_{0}$ and the broader range of $\xi$ become. This result can well explain the phenomenon found by Xiao et al. [9], who observed that it was more difficult for particles to coagulate at low temperature while it was easier to coagulate at high temperature.

At moderate coagulant dosages, the variation of particle surface charge is certainly more important than the increase of floc volume fraction [10]. So when sweep coagulation dominates the coagulation mechanism, volume of alum precipitates will not change the characteristic of floc surface.

When the size of micro-floc exceeds a certain value, it is easy for the floc to overcome the potential energy $V_{T}$, because its kinetic energy which is determined by orthokinetic collision (hydrodynamic shear gradients) can be higher than $V_{T}$. At this time, applied shear and characteristic of floc surface determine the coagulation efficiency.

As reported by Xiao et al. [9], there was no significant difference of coagulation rate between low and high temperatures. As shown in Fig. 3, when the alum dosage was in a certain range, coagulation rate showed little change, and here the characteristic of floc surface will be the dominant reason. Therefore, the zeta potential of flocs should not be the key factor when micro-flocs achieve a certain size.

In order to know whether residual dissolved aluminum will change during coagulation process, which may change the surface of micro-flocs and improve their connection, concentration of residual dissolved aluminum after adding $0.1 \mathrm{mM}$ alum $(2.7 \mathrm{mg}$ / L) was measured at $\mathrm{pH} 7.0$, as shown in Table 1. It can be seen that the concentration changed little during flocculation, which indicated that the connection of micro-flocs must be mainly dependent on some materials on the surface of micro-flocs.

The study of Phillips et al. [25] demonstrated that most Al-(hydr)oxide phases, such as bayerite, contain edge-linked Al octahedra with surfaces that also contain terminal water (and/or hydroxyls) and paired bridging hydroxyls which interact with the solvent. It is speculated that there are a quantity of $\eta_{2}-\mathrm{OH}_{2}$ on the surface of newly formed hydroxide precipitates, and it can react with $\eta_{2^{-}}$

Table 1

Concentration of residual dissolved aluminum at different time at $\mathrm{pH}$ 7.0.

\begin{tabular}{lllllll}
\hline Time (min) & 1 & 2 & 3 & 5 & 11 & 16 \\
\hline Residual Al (mg/L) & 0.0283 & 0.0292 & 0.0311 & 0.0330 & 0.0311 & 0.0339 \\
\hline
\end{tabular}




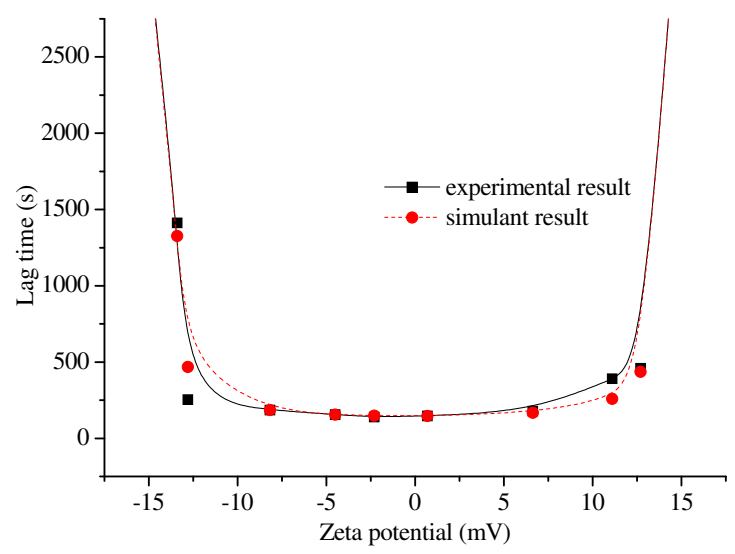

Fig. 6. Relationship between zeta potential and lag time.

$\mathrm{OH}$, which change into $\mu_{2}-\mathrm{OH}$ and $\mathrm{H}_{2} \mathrm{O}$ as $\mathrm{pH}$ increases. In this case, there are a lot of $\eta_{2}-\mathrm{OH}_{2}$ and $\eta_{2}-\mathrm{OH}$ in moderate $\mathrm{pH}$, while higher $\mathrm{pH}$ will cause lower quantity of $\eta_{2}-\mathrm{OH}_{2}$ and higher quantity of $\eta_{2^{-}}$ $\mathrm{OH}$, and lower $\mathrm{pH}$ will cause higher quantity of $\eta_{2}-\mathrm{OH}_{2}$ and lower quantity of $\eta_{2}-\mathrm{OH}$, respectively. As a result, the coagulation rate is relatively higher at moderate dosage and moderate $\mathrm{pH}$, as shown in Fig 3. This mechanism is of great significance to explain many phenomena in coagulation process and to further explore the coagulation mechanisms (see Fig. 6).

\section{Conclusion}

The main conclusions of this work are:

1. It was demonstrated that only 1 min rapid mixing was enough for adsorption of humic acid onto the precipitates of alum, and 15 min flocculation (slow mixing) only induced the formation and growth of flocs.

2. The primary particles size of alum-humic flocs was near $50 \mathrm{~nm}$. The formation of micro-flocs was determined by the square value of zeta potential and intensity of nano-sized primary particles (around $50 \mathrm{~nm}$ ) by Brownian motion, which is closely related with temperature. The higher temperature is, the broader range of zeta potential meeting high coagulation efficiency.

3. There must be a relationship between absolute zeta potential and lag time, and optimum coagulant dosage was at a zeta potential somewhat offset from zero.

4. The coagulation rate was determined by the surface activation of flocs rather than zeta potential of floc, after micro-flocs formed.

\section{Acknowledgement}

This work was also supported by National Natural Science Foundation of China (Grants 51108444 and 51138008). The work is also supported by the Young Scientist Project of State Key Laboratory of Environmental Aquatic Chemistry.

\section{References}

[1] B.A. Dempsey, R.M. Ganho, C.R. O'Melia, The coagulation of humic substances by means of aluminium salts, J. Am. Water Works Assoc. 76 (4) (1984) 141150.

[2] B.A. Dempsey, H. Sheu, T.T.M. Ahmed, J. Mentink, Polyaluminum chloride and alum coagulation of clay-fulvic acid suspensions, J. Am. Water Work Assoc. 77 (3) (1985) 74-80.

[3] G.A. Edwards, A. Amirtharajah, Removing color caused by humic acids, J. Am. Water Works Assoc. 77 (3) (1985) 50-57.

[4] J.E. Gregor, C.J. Nokes, E. Fenton, Optimising natural organic matter removal from low turbidity waters by controlled $\mathrm{pH}$ adjustment of aluminium coagulation, Water Res. 31 (1997) 2949-2958.

[5] J. Duan, J. Gregory, Coagulation by hydrolysing metal salts, Adv. Colloid Interface Sci. 100-102 (2003) 475-502.

[6] X.C. Wang, P.K. Jin, J. Gregory, Structure of Al-humic flocs and their removal at slightly acidic and neutral pH, Water Sci. Technol. 2 (2) (2002) 99-106.

[7] S.-H. Kim, B.-H. Moon, H.-I. Lee, Effects of $\mathrm{pH}$ and dosage on pollutant removal and floc structure during coagulation, Microchem. J. 68 (2001) 197-203.

[8] A.T. Hanson, J.L. Cleasby, The effect of temperature on turbulent flocculation: fluid dynamics and chemistry, J. Am. Water Works Assoc. 82 (11) (1990) 5673.

[9] F. Xiao, J. Ma, P. Yi, J.-C.H. Huang, Effects of low temperature on coagulation of kaolinite suspensions, Water Res. 42 (2008) 2983-2992.

[10] S.K. Dentel, Application of the precipitation-charge neutralization model of coagulation, Environ. Sci. Technol. 22 (7) (1988) 825-832.

[11] S.K. Dentel, Coagulation of Organic Suspensions with Aluminum Salts. Ph.D. Dissertation, Cornel University, Ithaca, NY, 1984.

[12] R.D. Letterman, D.R. Iyer, Modeling the effects of hydrolyzed aluminum and solution chemistry on flocculation kinetics, Environ. Sci. Technol. 19 (1985) 673-681.

[13] W.J. Snodgrass, M.M. Clark, C.R. O'Melia, Particle formation and growth in dilute aluminum(III) solutions: characterization of particle size distributions at pH 5.5, Water Res. 18 (4) (1984) 479-488.

[14] X. Li, B.E. Logan, Collision frequencies between fractal aggregates and small particles in a turbulently sheared fluid, Environ. Sci. Technol. 31 (4) (1997) 1237-1242.

[15] X. Li, B.E. Logan, Collision frequencies of fractal aggregates with small particles by differential sedimentation, Environ. Sci. Technol. 31 (4) (1997) 1229-1236.

[16] W. Xu, B. Gao, Q. Yue, Y. Wang, Effect of shear force and solution pH on flocs breakage and re-growth formed by nano- $\mathrm{Al}_{13}$ polymer, Water Res. 44 (6) (2010) 1893-1899.

[17] T. Liu, Z. Chen, W. Yu, J. Shen, J. Gregory, Effect of two-stage coagulant addition on coagulation-ultrafiltration process for treatment of humic-rich water, Water Res. 45 (2011) 4260-4268.

[18] J. Gregory, D.W. Nelson, Monitoring of aggregates in flowing suspensions, Colloids Surf. 18 (1986) 175-188.

[19] M.A. Yukselen, J. Gregory, The reversibility of floc breakage, Int. J. Miner. Process. 73 (2004) 251-259.

[20] F. Xiao, X. Zhang, J. Ma, Indecisiveness of electrophoretic mobility determination in evaluating $\mathrm{Fe}(\mathrm{III})$ coagulation performance, Sep. Purif. Technol. 68 (2009) 273-278.

[21] C.Z. Hu, H.J. Liu, J.H. Qu, D.S. Wang, J. Ru, Coagulation behavior of aluminum salts in eutrophic water: significance of $\mathrm{Al}_{13}$ species and $\mathrm{pH}$ control, Environ. Sci. Technol. 40 (2006) 325-331.

[22] F. Xiao, X. Zhang, C. Lee, Is electrophoretic mobility determination meaningful for aluminum (III) coagulation of kaolinite suspension?, J Colloid Interface Sci. 327 (2008) 348-353.

[23] H. Stechemesser, B. Dobias, Coagulation and Flocculation, second ed., Taylor \& Francis [M], 2005.

[24] W. Yu, J. Gregory, L. Campos, Breakage and re-growth of Al-humic flocs-effect of additional coagulant dosage, Environ. Sci. Technol. 44 (16) (2010) 63716376.

[25] B.L. Phillips, W.H. Casey, M. Karlsson, Bonding and reactivity at oxide mineral surfaces from model aqueous complexes, Nature 404 (6776) (2000) 379-382. 